\title{
The importance of understanding computer analyses in civil engineering
}

1 Alistair Borthwick PhD, DSc, CEng, FICE Professor of civil and environmental engineering, University College Cork, Ireland

2 John Carpenter BSC, CEng, FICE, CFIOSH Consultant structural engineer, J Z Carpenter Ltd, Manchester, UK

3 Barry Clarke PhD, CEng, FICE, FGS

Professor of civil engineering, geotechnics, University of Leeds, UK
4 Roger Falconer DSc(Eng), CEng, FICE, FREng $\mathrm{CH} 2 \mathrm{M}$ HILL-Halcrow professor of water management, Cardiff University, UK

5 Jon Wicks BSC, PhD, CEng, MICE Global technology leader, CH2M HILL, Swindon, UK
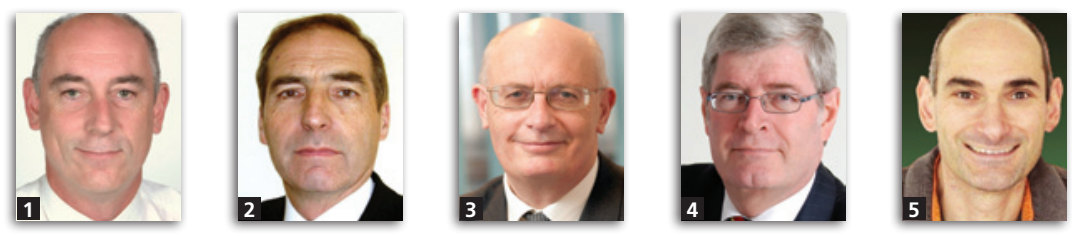

Sophisticated computer modelling systems are widely used in civil engineering analysis. This paper takes examples from structural engineering, environmental engineering, flood management and geotechnical engineering to illustrate the need for civil engineers to be competent in the use of computer tools. An understanding of a model's scientific basis, appropriateness, numerical limitations, validation, verification and propagation of uncertainty is required before applying its results. A review of education and training is also suggested to ensure engineers are competent at using computer modelling systems, particularly in the context of risk management.

\section{Introduction}

Most civil, structural and environmental engineering analysis is nowadays undertaken with the aid of computer modelling. Such modelling systems have undergone tremendous advances in recent years and permit analysis of micro and macro problems.

However, as models have advanced they have also become more complicated and sophisticated. Users need to know whether a particular model is scientifically appropriate, validated, verified and gives sensible results before they apply the model outputs.

The models have also become easier to use through, for example, the introduction of graphical user interfaces and thus a wide range of users may feel confident in using them. But these users may not have the same level of understanding of the underlying analysis, or physics and so on, as expert analysts.

It is obvious that uncritical and uninformed reliance on analysis software is detrimental in terms of safety, cost and best practice. Ultimately, this could lead to failures with disastrous consequences, ranging from economic loss and environmental damage to loss of life. So how should civil engineers embrace advances in computer modelling, in accordance with the expectations of society, while maintaining control of the associated risk?
In September 2011 the Institution of Civil Engineers held an event entitled 'Understanding our analysis' to open a dialogue on this subject. The event comprised four presentations which drew attention to the dangers of a blinkered approach to analysis, illustrated by examples taken from structural engineering, hydro-environmental modelling, flood management and geotechnical engineering. This paper has been written to disseminate to a wider audience the key points that arose during the event.

\section{A structural-engineering perspective}

Two examples from structural engineering demonstrate where a poor understanding of modelling and associated analysis can cause major failures.

The first is the Hartford Civic Center Arena roof failure in January 1978 in Connecticut, USA (see e.g. Martin and Delatte (2001)). The roof was a space frame that collapsed one night after heavy snowfall, fortunately without any fatalities or injuries. The roof was modelled using software that did not account properly for the eccentricity of the joints, where forces did not come together at a single point. It was failure to recognise this shortcoming in the analysis (among other things) that led to the failure. 
Despite the significant advances in modelling since then, ensuring that a model reflects reality with sufficient accuracy remains a key aspect.

The second example is Sleipner A, an offshore gravity platform that sank off the coast of Norway in August 1991. A leak occurred in the cellular wall of the base of the platform when it was undergoing controlled ballasting as part of the deck mating procedure during installation (Jakobsen and Rosendahl, 1994; Selby et al., 1997). The inquiry discovered that a direct cause of the failure was a major error in the finite-element analysis, where an element in shear was not correctly modelled.

A 'back of the envelope' check involving a few lines of hand calculation would have shown that the shell element was insufficiently reinforced and so could not withstand the fluid loading. Although contemporary software has many more checks and balances, it is still necessary for the modeller fully to appreciate the sensitivities and constraints when modelling complex structural components.

Structural engineering is almost invariably safety critical and so designers have statutory responsibility to ensure their analysis is correct, or at least adequate to safeguard life (Figure 1). It is vital that engineers are able to satisfy themselves that their numerical tools are properly validated, verified and give sensible outputs.

The underlying assumptions and limitations of any model must be assessed. Careful attention must be given to input data in terms of certainty and completeness. Validation provides assurance that the model is behaving as anticipated. The outputs should be checked for correctness, ultimate limit state and robustness. Sensitivity tests are a useful way to provide confidence in the results. Although a failure to predict serviceability performance will not endanger life, it may well have significant economic consequences.

Engineers should understand both the analysis and the design aspects of computer packages, many of which are integrated. In design, challenges are often encountered that are not readily modelled - such as buildability, robustness and local detailing - all of which must be properly considered. It is essential that leading checks and initial design be undertaken before using the more sophisticated model. As in many aspects of work, experience is an essential element of the design process and where this is not available it must be supplemented by way of supervision or checking and review procedures.

Engineers are risk managers, and understanding analysis falls within this remit. It seems obvious that engineering companies should adopt risk-management policies which cover the professional competency of the team, hazard elimination and risk reduction, preliminary and alternative analysis procedures, software validation and verification, sensitivity checks and intermediate gateway checks (whereby the analysis or design cannot proceed until certain criteria have been met).

Universities also need to educate young engineers in the key concepts of modelling and risk management, including how to cope with uncertainty and incomplete data.

\section{An environmental-engineering perspective}

Computational models are also increasingly used for environmental impact assessments because of the models' apparent capability to represent processes at prototype scale. Although hydro-environmental models have grown in complexity, they can

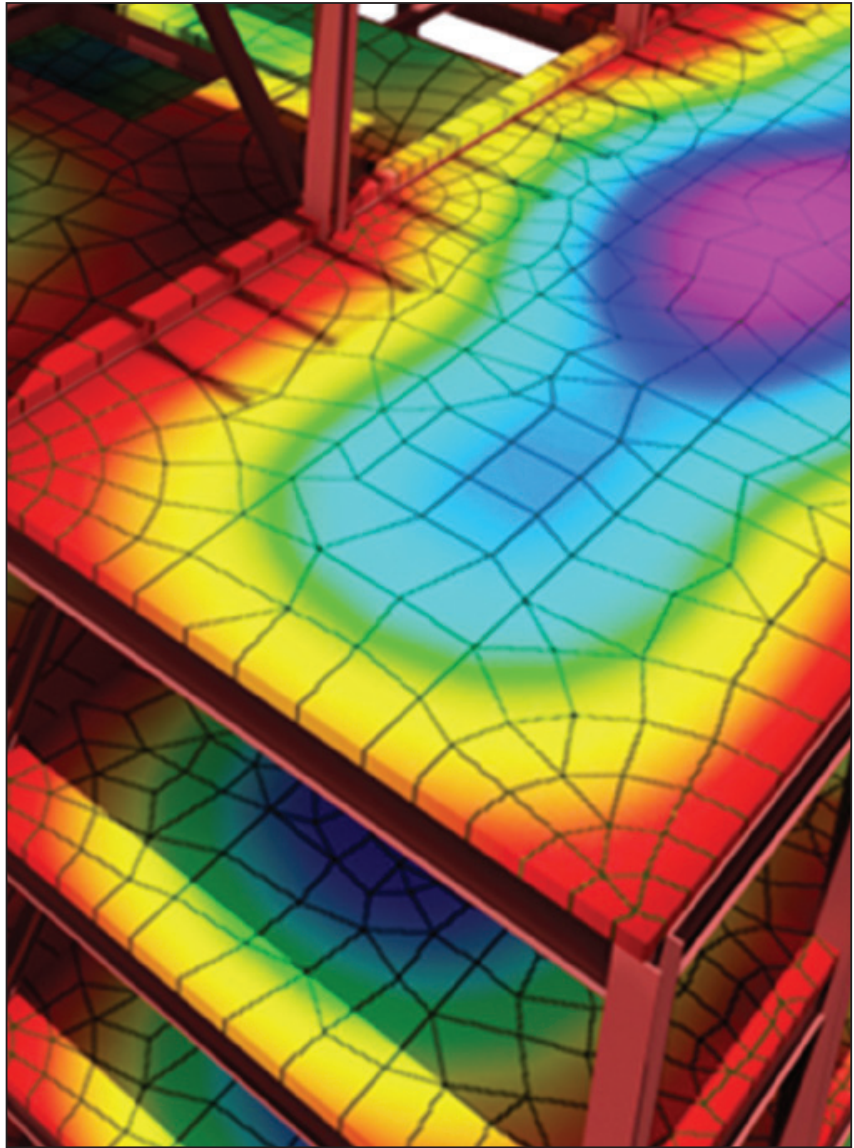

Figure 1. Structural engineering is almost invariably safety critical, so designers have statutory responsibility to ensure their analysis is correct, or at least adequate to safeguard life (courtesy of Autodesk)

give erroneous results if used inappropriately by inexperienced users with limited knowledge of both the models themselves and the complex processes being addressed. Moreover, at universities, the undergraduate curriculum does not include some of the key science underpinning current widely used hydro-environmental analysis tools.

Consider the numerical modelling of water quality in a typical estuarine basin. The flow domain is first divided into a very large number of elements and the seaward open boundary may be long and much unknown. The computer software solves millions of discretised equations for conservation of mass, momentum, solutes, pollutants, sediments, metals and so on. However, it is often the case that users have not studied the derivation of the conservation equations being solved and yet use the software to compute solutions to complex hydro-environmental problems.

Users need to be very aware of model limitations. There are flow uncertainties related to the underlying assumptions, such as the hydrostatic pressure assumption, a constant wind stress, steady and uniform flow for the bed-resistance term, and empirical representation for the bed resistance, turbulence, diffusion, dispersion and decay.

Turning to water quality, there are further uncertainties, including the values of turbulent diffusion and dispersion coefficients; 
(a)

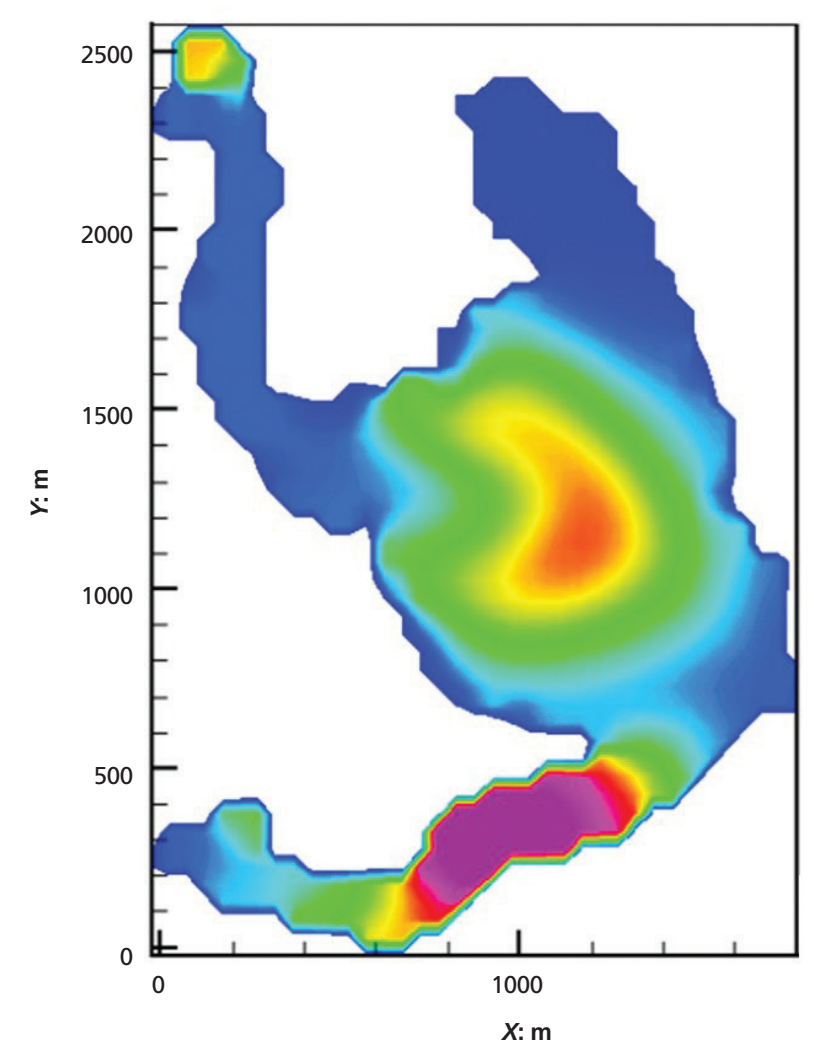

(b)

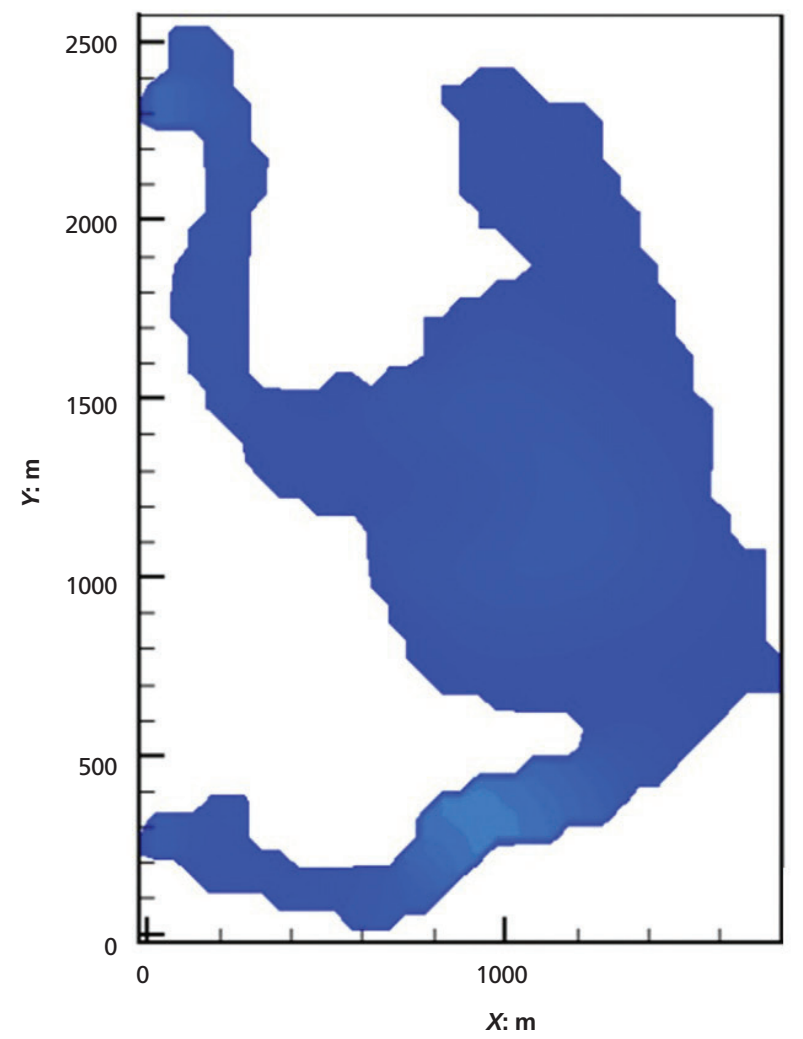

Figure 2. Model simulations of water quality after $12 \mathrm{~h}$ for two hypothetical coliform spills into Cardiff Bay for effluent releases from Cardiff Millennium Centre (top left) and sewage treatment works (bottom right) at (a) 4.00 p.m. and (b) 4.00 a.m. for different decay rates for day (0800-1700) and night (1700-0800) respectively - the simulations highlight the importance of incorporating the correct physics, in this case a combination of day and night decay rates, in the model

the variation of decay and kinetic rates with parameters such as temperature and sunlight; and the interaction of water quality indicators with salinity, sediments and so on.

There are also numerical model uncertainties. These include the treatment of the advective terms in the momentum and transport equations, grid size, time step, open boundary data, stochastic inputs, and the accuracy and reliability of field data used for calibration and validation. For example, much of the physical basis to the model representation is removed if a grid is too coarse, but too fine a grid may lead to excessive computational time requirements. Choice of time step should be such that it is not so large that periodic (e.g. tidal) behaviour is entirely missed or that the model becomes unstable, and not so small that the results are dissipative (see e.g. Abbott and Basco (1989)). Formal grid convergence and stability tests are good practice (see e.g. Roache (1998)).

Open boundaries pose awkward problems both with regard to location (avoiding reflection back into the domain of information propagating outwards) and the need for accurate input data. A major factor is the experience and training of model users. An example is that of a hypothetical sewage effluent discharge entering Cardiff Bay, Wales, after a major international sports event at the Millennium Stadium. In this case study (Harris et al., 2002), the water quality is dependent on the bacterial decay rate of human effluent.
The majority of commercially available hydro-environmental models use constant decay rates, but the bacterial decay rate of sewage is a function of sunlight, irradiance, depth, $\mathrm{pH}$, temperature, turbidity and so on. Measurements in Cardiff Bay have shown that the decay rate is best expressed as a combination of different day and night decay rates (noting that there is virtually no decay at night). Model predictions using this more accurate decay rate show that the water quality varies considerably depending on the time the sewage is released into Cardiff Bay (Figure 2). Had a constant decay rate been used, there would have been no difference between the results, which is incorrect.

Hydro-environmental impact-assessment studies are based on increasingly complicated software. As a consequence, hydroenvironmental modellers require multidisciplinary skills, based on a thorough grounding in science and numerical methods.

\section{A flood-modelling perspective}

Flood modelling involves the use of numerical models to predict water flows, depths, velocities and inundation extents resulting from extreme events such as unusually heavy rainfall, storm surges and dam breaks. Flood modelling is useful at assessing countermeasures and mitigation options. It relies on geographical and hydrological 
The importance of understanding computer analyses in civil engineering

Borthwick, Carpenter, Clarke, Falconer and Wicks input data, and on the software tools themselves.

Most importantly flood modelling relies on the people who develop and operate flood models, interpret results and convey the information to stakeholders (such as homeowners, businesses, insurers, government agencies and politicians). Inaccurate predictions can result in a range of problems, such as flood warnings not being issued when a flood is about to occur or flood defence works being under-designed - both of which can have negative socio-economic consequences.

Good practice in flood modelling starts with a concept review, whereby an expert panel meets to identify the best modelling approach. Data are then collected and the model constructed and subjected to initial testing to assess the broad-scale reasonableness of model behaviour when subject to sample input data. This initial testing may lead to changes in the model structure, input data or review of observational data.

Next, model calibration is undertaken by adjusting input parameters until the predictions match observations, if available. Particularly where observations are not available, sensitivity analysis is used to 'sense check' model outputs and derive data to support confidence statements.

A further model review is then undertaken (preferably by the same expert panel) to assess whether the model is providing a sufficiently correct representation of reality for the intended use of the model. If not the model may undergo further calibration, or more data be acquired and input or the entire approach changed. Once the model is judged acceptable, production runs are undertaken to generate results.

A further formal review is recommended to assess whether the final outputs (e.g. flood maps) make sense. If approved the results can then be used to inform decision making.

Flood modelling underpins modern flood risk management. Flood maps are used to locate new developments away from flood-prone areas, to enhance emergency planning procedures, to carry out economic appraisal of different flood-management options, to raise public awareness and to provide information for insurance purposes.

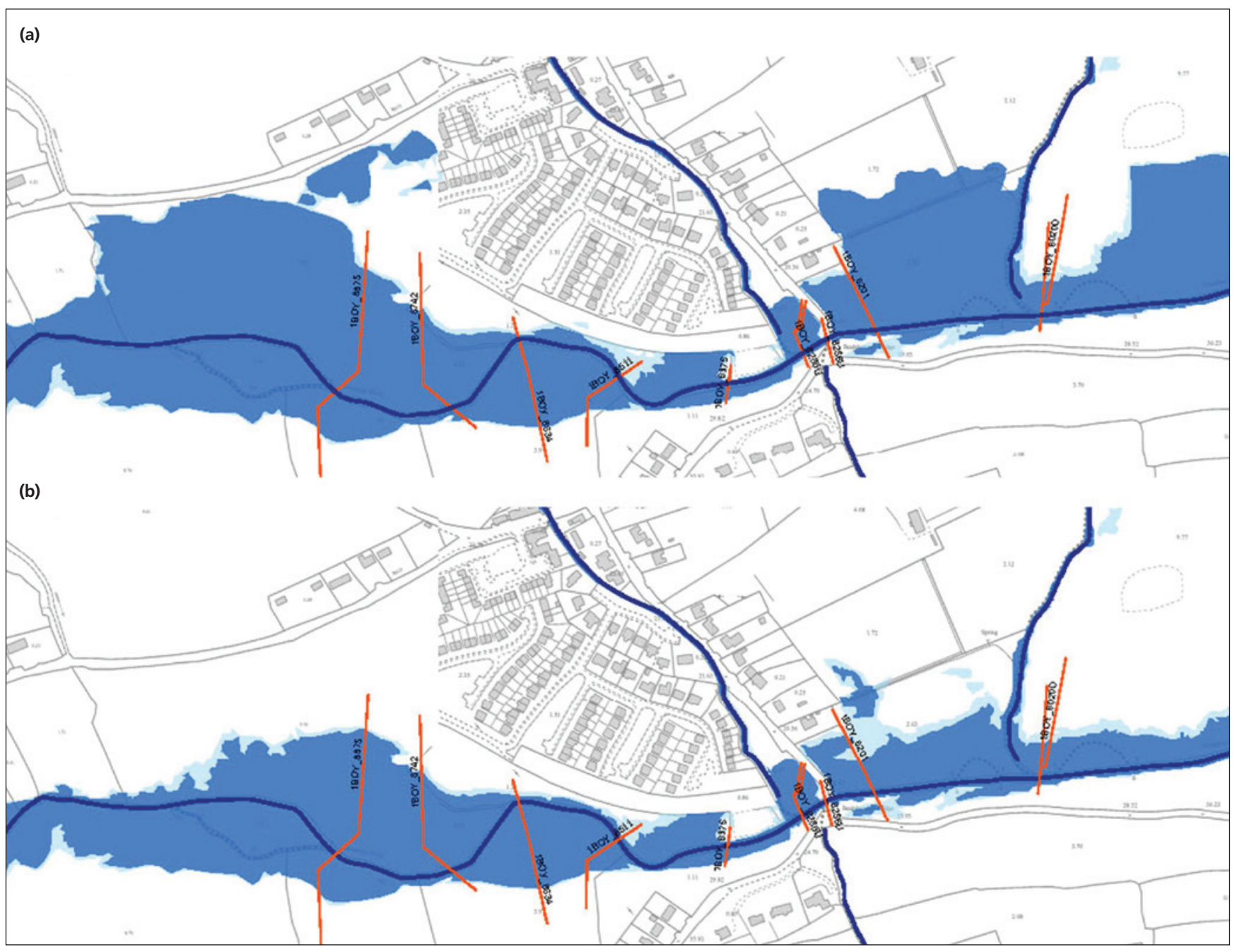

Figure 3. Example flood mapping problem: (a) incorrect post-processing due to a user incorrectly applying geographic information system analysis to determine the water surface predicted by a one-dimensional hydraulic model by intersection with a digital terrain model; (b) corrected postprocessing when the user excluded the overlaying of water levels from tributaries on the primary river floodwater surface elevations - the problem was not straightforward to identify due to a lack of validation data 
Civil Engineering

Volume 166 Issue CE3 August 2013
The importance of understanding

computer analyses in civil engineering

Borthwick, Carpenter, Clarke, Falconer and Wicks
Water levels predicted by flood models are used in the design of flood defence works. Importantly flood modelling is used in flood forecasting to enable accurate and timely warnings to be issued.

There are many issues that can arise. For example, improper postprocessing of perfectly valid results can lead to the production of highly inaccurate flood maps. Figure 3 shows what happened when an inexperienced user incorrectly applied geographic information system analysis to intersect the floodwater surface generated from one-dimensional modelling of both the main river and its tributaries with a digital terrain model when producing a flood map.

The upper map resulted from the incorrect analysis, which significantly overestimated the flood extent on the north side of the main river. Although checks were performed, the error was not initially spotted due to there being no previous record of flooding in this area and so it was impossible to compare the calculated with observed flood extents. The lower map shows the corrected flood map in which the water levels from the tributaries were excluded from the floodwater surface generated for the main river.
This example illustrates the additional difficulty in assessing flood modelling outputs where verification data are unavailable.

Another issue is the probabilistic nature of the outputs of flood analysis. Figure 4 shows two different predictions of the flood extent map for a 1:100 year event for Carlisle. Both maps, although quite different, have been generated using the same model but with slightly adjusted input parameters and different assumptions (e.g. flows in the different tributaries). Figure 4(a) provides what is probably the best estimate, with a 50\% chance (or likelihood) that the flood extent will lie within the blue area; Figure 4(b) a $96 \%$ chance that the flood extent will lie within the blue area.

In both cases there is also a likelihood that the flooding could be outside the blue area. The difference between the maps is not due to any errors in the processing, which involved 3000 different simulations taking account of various input data uncertainties and the influence of the tributaries. In this case, there is no uniquely correct flood map. Instead, the probabilistic approach to the analysis gives useful information to decision makers.
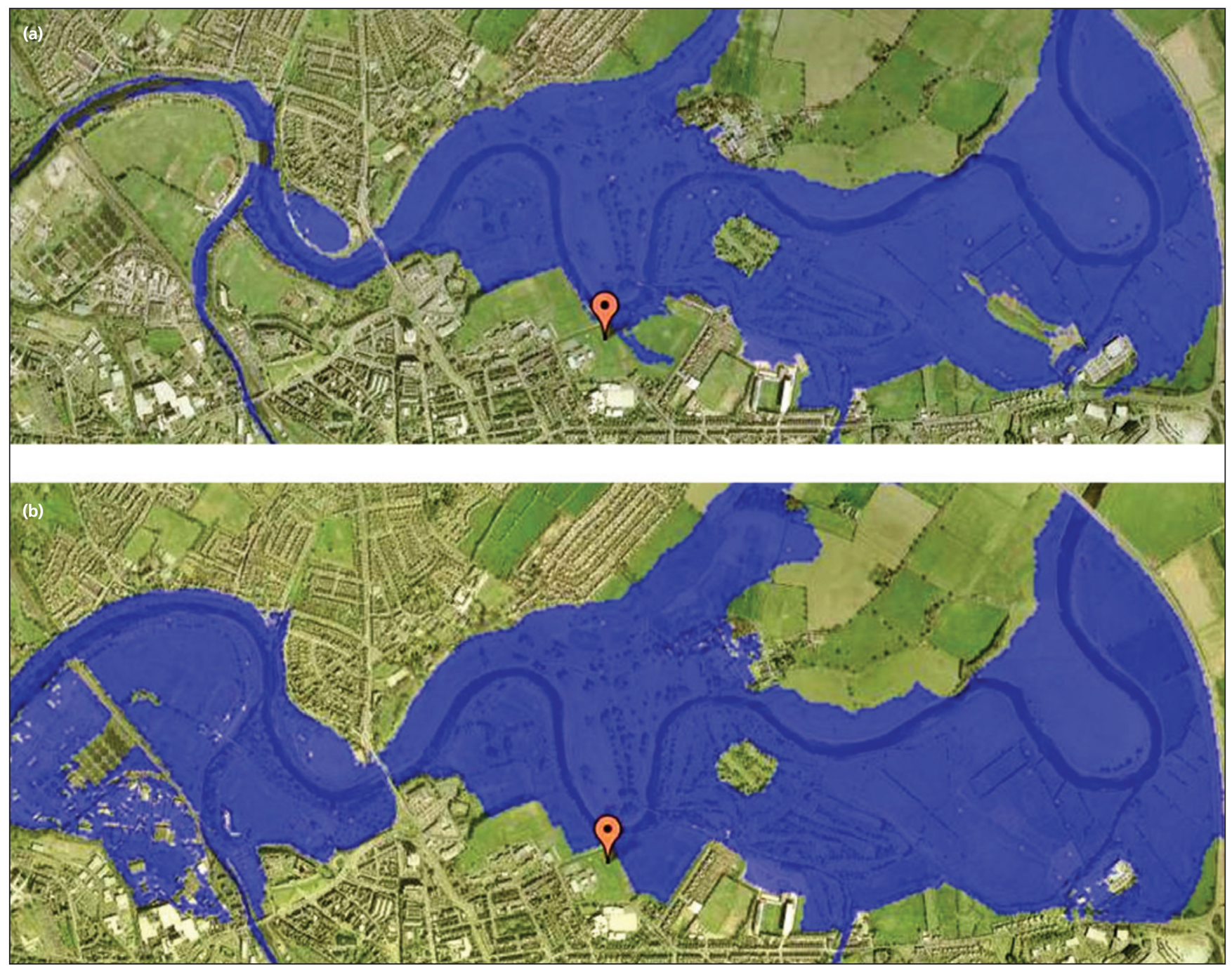

Figure 4. Flood extent maps illustrating the likelihood of 1:100 year flood extent for Carlisle, England: (a) 50\% likelihood; (b) 96\% likelihood. The maps illustrate the application of a probabilistic approach to the understanding of flood extent (courtesy University of Lancaster / Flood Risk Management Research Consortium, www.lancs.ac.uk/staff/leedald/Carlisle/visualisation.html). 
Flood modelling only provides an approximate representation of reality. There tend to be large residual uncertainties. The modelling process involves many decision steps at which different modellers may legitimately make different decisions. Most importantly the scarcity, natural randomness and statistical non-stationarity in the environmental input data usually have a significant impact on results.

To help inform better decision making there needs to be a move towards a method that includes communication of uncertainty and spatially varying flood likelihood (Beven et al., 2010). Users would then be better able to assess whether the output information is good enough for what they are trying to achieve.

Although major advances have occurred in flood modelling in the last 20 years, improvements need to be made to the analysis process through education and training of users. Engineers need to understand the scientific and numerical fundamentals, know how to select, validate, verify and use the most appropriate modelling approach, and know how to assess the outputs critically.

Users must develop a better appreciation of how uncertainties in input data propagate through to the outputs. It is also vital that users are able to communicate clearly their findings to clients, the public and other stakeholders.

Guidance documents are essential for improving analysis approaches. Examples include European guidance on flood mapping good practice (Martini and Loat, 2007), a validation framework for flood modelling (Wicks and Horritt, 2012) and a framework for assessing uncertainty in flood risk mapping (Beven et al., 2010). A significant contribution to benchmarking of two-dimensional flood models is provided by the UK Environment Agency (Néelz and Pender, 2010).

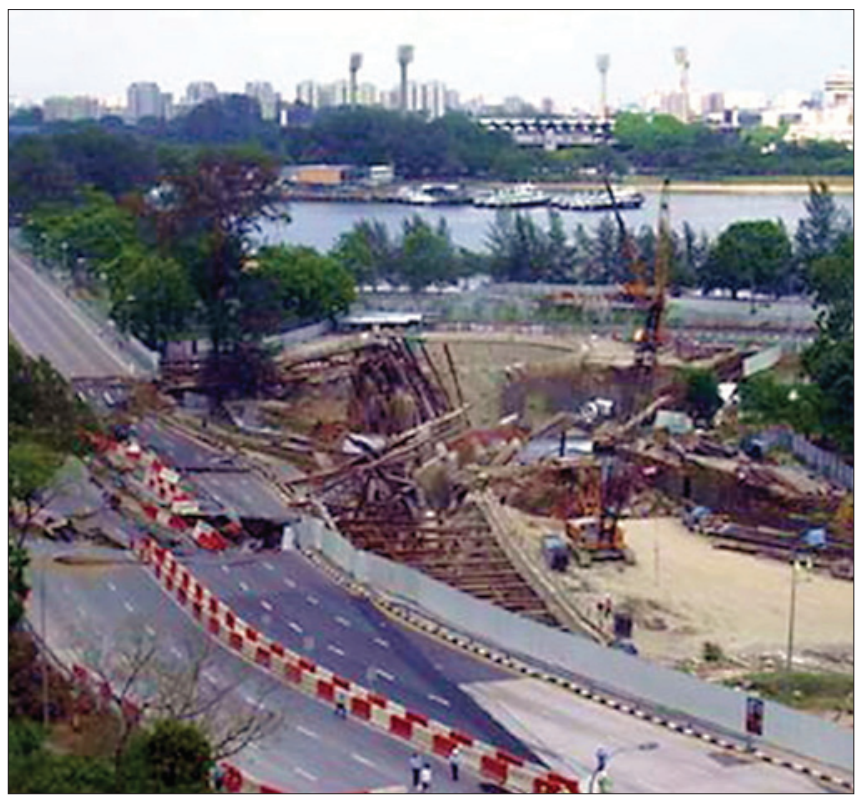

Figure 5. Retaining wall collapse at Nicoll Highway, Singapore in 2004 during construction of the mass rapid transit - investigations suggested the most likely cause lay in the design of the retaining wall, which proved insufficient to resist the earth pressure. This was attributed to the use of an inappropriate soil model, which overestimated the soil strength at the site and underestimated the forces on the retaining walls in the excavation

\section{A geotechnical-engineering perspective}

Geotechnical engineering involves significant uncertainties, especially when one considers how little is known about the subterranean characteristics of any given site. Competence, relevance and performance are very important to geotechnical analysis.

Society expects professional engineers to be competent - and this applies when engaged in analysis. In practice, however, misuse of software is not uncommon because of a lack of understanding of the underlying science including that of the chosen soil model.

Figure 5 shows a civil engineering failure of an excavation at Nicoll Highway, Singapore in 2004, where four construction workers were tragically killed. An international panel of experts appointed by the Singapore government found that the collapse occurred because the engineer responsible for the analysis did not understand the software, the constitutive model and the local ground conditions.

Site investigations and analysis should be relevant. Yet the routine ground investigations recommended by Eurocode 7 (BSI, 2010a, 2010b) do not provide the data needed for the constitutive models used in typical commercial analysis packages for Coulombhardening soft soils. Consequently, it is necessary to use fudge factors and learn from experience when applying the analysis package.

Many questions arise. Why not undertake relevant site investigations? Given the many different constitutive models in commercial codes, which one should be selected for a given application? Is the constitutive model correct? Are the limitations understood? Does this mean that any analysis can be at best an estimate of what is going to happen?

Eurocode 7 states

Knowledge of the ground conditions depends on the extent and quality of the geotechnical investigations. Such knowledge and the control of workmanship are usually more significant to fulfilling the fundamental requirements than is precision in the calculation models and partial factors ... Reliable measurements of the stiffness of the ground are often very difficult to obtain from field or laboratory tests. In particular, owing to sample disturbance and other effects, measurements obtained from laboratory specimens often underestimate the in situ stiffness of the soil. Observations of the behaviour of previous constructions should therefore be analysed wherever available. (BSI, 2010a: pp. 22, 41)

Eurocode 7 places more emphasis on understanding ground conditions than improving calculation models. A paradigm shift is occurring from the use of failure criteria to fitness of purpose. Consequently, stiffness measurements are necessary. But the sampling procedure alters the ground stiffness, making it almost impossible to obtain the characteristic stiffness using routine investigation.

Of great importance is the need for more observations of existing structures to validate any analysis. In the UK, ground investigations are often not fit for purpose. Ground conditions can be extremely variable. Are the analysis models suitable for soil? What are the effects of assumptions in the numerical model on the analysis? Does a database exist by which to validate the analysis for a new site? What are the limitations of the analysis? The programmers probably do know these, but what about the users? 
Performance depends on data. In geotechnical engineering, the implementation of Eurocode 7 highlights the need for regional databases of geological and geotechnical information to improve the selection of characteristic design values and to reduce uncertainties in assigning design values.

Three-dimensional geological and geotechnical ground models will lead to risk reduction by improving the detailed representation of the ground. The performance of geotechnical structures needs monitoring and assessment.

Case studies are badly needed for reference by geotechnical engineers. To enhance future designs, it is vital that understanding be improved of the performance of geotechnical structures.

\section{Concluding remarks}

The world is becoming ever-more complex. Civil, structural and environmental engineers have to collect information, analyse it and then apply the results. There is no failsafe against incompetence or negligence - so if users carry out analysis without fully understanding what they are doing, then the likelihood of failure and possibly disaster is increased.

Society expects engineers to be competent, or to be under suitable supervision, which infers a contemporary understanding of their analysis and its application. Engineers have a duty to be aware of relevant key publications such as codes of practice, journal articles, key text books and guidance documents. This needs to be appreciated by all engineers.

Only users with proven competency should be permitted to model complicated processes using sophisticated computational techniques. Field data are vitally important for model validation. Engineers require education (at university) and training (in industry) to develop the skill sets necessary to cope with the demands of modern analysis techniques. Three key words summarise what is required: competence, relevance and performance.

It is time that a review is undertaken into the education and training of engineers in order to prepare them to be competent users of modern computer modelling systems and be risk managers. A bipartite action plan is needed: one aspect looking at management policies, the other looking at education.

\section{Society expects engineers to be competent, or to be under suitable supervision, which infers a contemporary understanding of their analysis and its application. Engineers have a duty to be aware of relevant key publications such as codes of practice, journal articles, key text books and guidance documents. This needs to be appreciated by all engineers.}

\section{References}

Abbott MB and Basco DR (1989) Computational Fluid Dynamics: an Introduction for Engineers. Longman Scientific and Technical, Harlow, UK.

Beven K, Leedal D, McCarthy S et al. (2010) Framework for Assessing Uncertainty in Fluvial Flood Risk Mapping. Flood Risk Management Research Consortium, Swansea, UK, research report SWP1.7. See http://web.sbe.hw.ac.uk/frmrc/downloads/Framework_for_Assessing_Uncertainty_Fluvial_Flood_Risk_Mapping_WP1_7. pdf (accessed 09/05/2013).

BSI (2010a) BS EN 1997-1: 2004: Eurocode 7: Geotechnical Design: Part 1 General Rules. BSI Group, London UK.

BSI (2010b) BS EN 1997-2: 2007: Eurocode 7: Geotechnical Design: Part 2 Ground Investigation and Testing. BSI Group, London, UK.

Harris EL, Falconer RA, Kay D and Stapleton C (2002) Development of a modelling tool to quantify faecal indicator levels in Cardiff Bay. Proceedings of the Institution of Civil Engineers - Water and Maritime Engineering 154(2): 129-135.

Jakobsen B and Rosendahl F (1994) The Sleipner platform accident. Structural Engineering International 4(3): 190-193.

Martin R and Delatte NJ (2001) Another look at the Hartford Civic Center Coliseum collapse. ASCE Journal of Performance of Constructed Facilities 15(1): 31-36.

Martini F and Loat R (eds) (2007) Handbook on Good Practices for Flood Mapping in Europe. EXCIMAP (European Exchange Circle on Flood Mapping), European Commission, Brussels, Belgium. See http://ec.europa.eu/environment/water/flood_risk/flood_atlas/pdf/handbook_goodpractice.pdf (accessed 09/05/2013).

Néelz S and Pender G (2010) Benchmarking of 2D Hydraulic Modelling Packages. Heriot Watt University for the Environment Agency, Bristol, UK, report SC080035/

SR2. See https://publications.environment-agency.gov.uk (accessed 09/05/2013).

Roache PJ (1998) Verification and Validation in Computational Science and Engineering. Hermosa Publishers, Albuquerque, NM, USA.

Selby RG, Vecchio FJ and Collins MP (1997) The failure of an offshore platform. Concrete International 19(8): 28-35.

Wicks J and Horritt M (2012) A Framework for Validating Probabilistic (Flood) Models. Halcrow for the Environment Agency, Bristol, UK, report SC090008/S2. 